\title{
Workers Who Stay at Work Despite Chronic Nonspecific Musculoskeletal Pain: Do They Differ from Workers with Sick Leave?
}

\author{
Haitze J. de Vries • Michiel F. Reneman • \\ Johan W. Groothoff • Jan H. B. Geertzen • \\ Sandra Brouwer
}

Published online: 28 March 2012

(C) The Author(s) 2012. This article is published with open access at Springerlink.com

\begin{abstract}
Purpose Most workers with chronic nonspecific musculoskeletal pain (CMP) do not take sick leave, nor consult a health care professional or search vocational rehabilitation. Yet, the knowledge of many researchers, clinicians and policy makers is largely based on people with CMP who discontinue work. The aim of this study was to explore characteristics of workers who stay at work despite CMP, and to compare these with sick-listed workers with CMP following vocational rehabilitation. Methods The clinical characteristics of workers who stay at work despite CMP $(\mathrm{n}=119)$ and sick-listed workers who follow vocational rehabilitation $(n=122)$ were described and the differences between these groups were assessed. Logistic regression analysis was used to assess differences between the groups and to determine which variables predicted group status. Results Workers who stayed at work despite CMP reported significantly lower levels of fear avoidance $(\mathrm{OR}=0.94)$, pain catastrophizing $(\mathrm{OR}=0.93)$, perceived workload $(\mathrm{OR}=0.93)$, and higher pain acceptance $(\mathrm{OR}=1.11)$, life control $(\mathrm{OR}=1.62)$ and pain self-efficacy $(\mathrm{OR}=1.09)$ compared to sick-listed workers following rehabilitation, even after controlling for confounders. The groups did not differ on physical activity level, active coping and work satisfaction. Group status
\end{abstract}

\footnotetext{
H. J. de Vries $(\square)$ · M. F. Reneman · J. H. B. Geertzen Department of Rehabilitation Medicine, Center for Rehabilitation, University Medical Center Groningen, University of Groningen, P.O. Box 30.002, 9750 RA Haren, The Netherlands

e-mail: h.j.de.vries@cvr.umcg.nl

J. W. Groothoff · S. Brouwer

Department of Health Sciences, Community and Occupational

Medicine, University Medical Center Groningen,

University of Groningen, Groningen, The Netherlands
}

was predicted best by pain intensity, duration of pain, pain acceptance, perceived workload, mental health, and psychological distress (area under the receiver operating characteristic curve $=0.91,95 \% \mathrm{CI}=0.87-0.95$ ). Conclusions A wide range of characteristics of workers who stay at work despite CMP were explored. Relevant differences from sick-listed workers with CMP were observed in all domains of the bio-psycho-social model. Six main predictors were identified that best discriminate between both groups.

Keywords Staying at work - Vocational rehabilitation . Musculoskeletal disorders · Chronic pain · Work participation

\section{Introduction}

The reference of many researchers, clinicians and policy makers concerning work and pain is based on people with chronic nonspecific musculoskeletal pain (CMP) who were not longer able to participate in work. However, by far not all workers with CMP become work-disabled [1-3], nor do they consult a health professional [4-6] or search multidisciplinary rehabilitation. Many workers are able to cope with CMP at work and maintain their employment. It is currently unknown on which factors people who stay at work despite CMP (SAW group) differ from people who are on sick leave and referred for rehabilitation (SL-Rehab group).

Most research has focused on sick leave and work disability of people with CMP [7-9]. Several predictors or associations for work disability have been identified, such as fear avoidance [10, 11], catastrophizing [12, 13], de-conditioning $[14,15]$, pain acceptance [16, 17], emotional distress [18, 19], life control and self-efficacy [20,21]. Our knowledge about 
staying at work with CMP, however, is limited. A literature review to identify factors that promote staying at work in workers with CMP revealed only 7 studies [22]. It was concluded that perceived physical disability and emotional distress are associated with staying at work (low level of evidence). Most studies investigating work participation in workers with CMP focused on absent or disabled workers and did not report on the successful counterpart that remained at work. To learn more about this large but relative "unknown" group, the project Working with Pain was conceived. In this project, staying at work was defined as sustained work participation despite CMP, with a maximum of $5 \%$ sick leave over a period of 12 months for CMP reasons. Because this group can be considered as the long-term goal of vocational rehabilitation, we expected that lessons can be learned from these successful workers. Specific attention to this SAW group may broaden our views on chronic pain and work participation. Factors associated with sick leave or disability may also explain why some people succeed to stay at work, where others fail $[13,23]$. The theory of fear avoidance describes how people with CMP develop catastrophizing thoughts and inactivity, then become deconditioned, which explains why they develop chronic pain and ultimately are susceptible for work disability. "Acceptance and Commitment Therapy" postulates that people may achieve better adjustment to CMP by learning to reduce avoidance and other attempts to control pain and choosing to direct their efforts on important lifevalues such as work [16]. People with high levels of stress may easily get trapped in a vicious circle, in which pain and distress reinforce one another. Relief of emotional distress may help people to stay at work $[19,24]$. The person's belief of having control over events may determine the behavior to fulfill its goals [25]; high feelings of control may initiate actions to enhance workability and staying at work. Self-efficacy beliefs determine "how much effort people will expend and how long they will persist in the face of obstacles and aversive experiences" [26-28]. Vocational rehabilitation operates at the interface of work and health care, where a bio-psycho-social approach is required to offer appropriate care. Therefore, a range of variables and corresponding measures were investigated in this study, sufficient to cover most essential domains for work participation: demographic, physical, psychological and work characteristics. It was assumed that if modifiable factors that associate with staying at work are known, it would give new insights for the development of effective vocational rehabilitation programs. Moreover, the knowledge gathered in this study might provide data towards a new reference for clinicians and researchers working in rehabilitation and occupational medicine.

The first aim of this study was to describe physical, psychological and work characteristics of workers in a SAW group. The second aim was to compare these characteristics with a SL-Rehab group and healthy working controls. Our hypotheses regarding the SAW and SL-Rehab group were that compared to the SL-Rehab group, workers in the SAW group report: higher levels of daily activity (hypothesis 1; H1); lower levels of fear avoidance beliefs about physical activity (H2) and pain catastrophizing (H3); higher pain acceptance $(\mathrm{H} 4)$; lower psychological distress (H5); better life control (H6) and self-efficacy (H7); better active coping (H8); lower perceived physical workload (H9) and higher work satisfaction (H10). Ultimately, the third aim was to examine on which variables the two groups can be distinguished the best.

\section{Methods}

Design

In a cross-sectional design the characteristics of workers with CMP in a SAW group and SL-Rehab group were measured in order to compare both groups.

\section{Subjects}

Eligible participants of the SAW group were recruited from May 2009 to December 2010 by announcements in newspapers, and websites of national patient associations of whiplash and fibromyalgia. It was made clear that they participated in scientific research and that no treatment or advice would be provided. A compensation of $€ 50$ and traveling compensation was offered for participation. Inclusion criteria were: diagnosed as CMP (pain in back, neck, shoulder, extremities or disorders such as widespread pain, fibromyalgia and whiplash) without known underlying specific medical cause (e.g., infection, neoplasm, metastasis, osteoporosis, rheumatoid arthritis, fracture, neurological disorders, and serious spinal pathology); duration of pain was longer than 6 months; age 20-60 years; paid work for $20 \mathrm{~h}$ or more during the 12 months before participation in the study. Exclusion criteria in this study were the following: relevant co-morbidities with severe negative consequences for physical and/or mental functioning (for example severe psychiatric disease or addiction to drugs), pregnancy, and insufficient knowledge of the Dutch language. Participants must have sustained work participation despite CMP, operationally defined as a maximum of 5\% sick leave ascribed to CMP over a period of 12 months (which is around the average rate of sickness absence in The Netherlands) [29, 30]. Participants did not seek help in a Rehabilitation Center in the year prior to participation.

Workers in the SL-Rehab group were consecutively included from July 2009 to March 2011. The SL-Rehab group was referred for vocational rehabilitation, a 
multidisciplinary approach that is provided to individuals of working age with health-related impairments, limitations, or restrictions with work functioning and whose primary aim is to optimize work participation [31]. Inclusion and exclusion criteria for the SL-Rehab group were the same as for the SAW group, except for absence at work caused by the pain in the SL-Rehab group was higher than $5 \%$ in the year prior to participation.

Sample size was determined by the amount of independent variables we intended to include into a logistic model. A minimum of 10 subjects per independent variable has been recommended [32]. Because we estimated to use 20 predicting variables in the model, a total sample size of at least 200 was needed.

In literature, norm scores or reference data of healthy controls were available for most of the used measures in our study. These reference data were obtained from working healthy controls, aged between 20 and 60 years.

\section{Procedures}

To diagnose the type of pain and the existence of co-morbidities, all participants from both groups received medical examination performed by a physiatrist. All participants completed questionnaires assessing demographic data and physical, psychological and work characteristics. The SL-Rehab group completed the work related questionnaires in relation to their most recent job experiences. Measures were taken prior to the rehabilitation program. Most of the questionnaires are used in usual care of patients in rehabilitation. The study was approved by the Medical Ethical Committee of the University Medical Center Groningen. All participants signed informed consent.

\section{Measures}

\section{Demographic Characteristics}

Demographic characteristics were gathered by a questionnaire constructed by Rehabilitation Development Centers in the Netherlands [33].

\section{Physical Characteristics}

Pain intensity Current pain intensity was measured by the 11-point Numeric Rating Scale (NRS), ranging from 0 (no pain) to 10 (worst imaginable pain). Validity and utility of the NRS is sufficient [34, 35].

Disability The Pain Disability Index (PDI) was used to measure the degree to which chronic pain interferes with daily activities (self perceived disability). The PDI is a 7-item inventory, each item score ranging from 0 (no interference) to 10 (total interference). The reliability and validity of the PDI is sufficient [36, 37]. Higher scores reflect higher interference of pain with daily activities. Reference data were obtained from a German population [38].

Health The Dutch version of the RAND 36-item Health survey (RAND-36) was used to measure physical health [39]. The subscales physical functioning, role limitations arising from physical health problems, pain, and general health perception were merged into the Physical Component Summary [40]. Scores range from 0 to 100, and higher scores reflect better perceived physical health. The Dutch version of the RAND 36-items is a reliable, valid and sensitive instrument [39]. Reference data were obtained from a Dutch population [39] and from a Dutch reference sample of healthy workers [41].

Activity level The Baecke Physical Activity Questionnaire (BPAQ; 16 items) was used to assess the total daily physical activity level of participants, reflected by 3 subscales work, sports and (non-sport) leisure time. Higher scores reflect higher perceived activity level. The BPAQ is presented as a valid and reliable instrument [42, 43]. Reference data were obtained from a Dutch reference sample of healthy workers [41].

\section{Psychological Characteristics}

Mental health The RAND-36 was used to measure mental health. The subscales social functioning, role limitations caused by emotional problems, mental health, and vitality were merged into the Mental Component Summary [40]. Scores range from 0 to 100 , and higher scores reflect higher perceived mental health.

The Symptom Checklist-90-Revised (SCL-90-R; 90 items) was used to measure psychosocial distress. The total score, the Global Severity Index (GSI), is reflected by the sum of all sub scores as a global measure of psychological distress. Higher scores reflect higher perceived psychological distress. Reliability and validity of the SCL-90-R are good [44, 45]. Reference data were obtained from a Dutch population [45].

Acceptance Pain acceptance was assessed using the Chronic Pain Acceptance Questionnaire (CPAQ; 20 items) [46, 47], consisting of two subscales: Activity Engagement (participation in daily activities while acknowledging the presence of pain) and Pain Willingness (the degree to which pain is allowed in experience without efforts to avoid or control it). Higher scores reflect higher perceived acceptance of pain. Validity and reliability of the CPAQ are reasonable [48-50]. Reference data were not available. 
Avoidance Fear avoidance beliefs about physical activity and (re)injury was measured with the Dutch version of the Tampa Scale of Kinesiophobia (TSK; 17 items) [51, 52]. Higher scores reflect higher perceived fear of physical activity. Reliability and validity of the Dutch version are good [52, 53]. Reference data of a healthy working group were not available.

Self-efficacy Pain self-efficacy was measured by the Dutch version of the Pain Self Efficacy Questionnaire (PSEQ; 10 items). Each item is rated by selecting a number on a 7-point scale, scores ranging from 0 ("not at all confident") to 6 ("completely confident"). Higher scores reflect stronger self-efficacy beliefs. Self-efficacy beliefs for people experiencing chronic pain incorporate not just the expectation that a person could perform a particular behavior or task, but also their confidence in being able to do it despite their pain [54]. The PSEQ has strong psychometric properties and high reliability and validity [28].

Catastrophizing Pain catastrophizing was measured by the Dutch version of the Pain Catastrophizing Scale (PCS; 13 items) [55, 56]. Higher scores reflect stronger experienced thoughts and feelings of participants while they are in pain. The PCS showed to be valid and highly reliable [56-58]. Reference data were obtained from a Dutch community sample without pain [59].

Coping reactions were measured by the Utrecht's Coping List (UCL; 47 items), distinguished by the following subscales: active coping, palliative reaction, avoidance, social support, passive coping, expression of emotions and coping self statements. Higher scores reflect higher levels of coping reactions. The UCL is validated for patients with chronic pain [60]. Reliability and validity are moderate to good [61]. Reference data were obtained from a Dutch population [61].

Interference of pain in daily life: The Dutch version of the West-Haven Yale Multidimensional Pain Inventory (MPI-DV; 21 items) was used to assess the subjects' level of life control (incorporating the ability to solve problems and feelings of personal mastery and competence); mood (including ratings of depressed mood, irritability and tension); support received from spouse; and responses of significant others to their pain behavior (punishing, solicitous, and distracting responses). Higher scores reflect stronger feelings of life control, better mood, higher perceived support and more responses of significant others. The reliability and validity of the MPI are good [62, 63].

\section{Work Characteristics}

Vocational sector, perceived workability, sick leave during previous 12 months, and expectation to fulfill future work were assessed with the Work Ability Index (WAI). The reliability and validity of the WAI are acceptable [64, 65].

Presenteeism was assessed with the World Health Organization's Health and Work Performance Questionnaire (HPQ). Presenteeism was conceptualized as a measure of actual performance in relation to possible performance, scored as percent of performance on a $0-10$ response scale, where 0 represents a total lack of performance and 10 no lack of performance during time of the job. The HPQ is a reliable and valid measure [66, 67].

Work pace, emotional workload, relation with colleagues or supervisor, work satisfaction, and need for recovery were assessed by the Dutch questionnaire on the Perception and Evaluation of Work (Dutch abbreviation: VBBA) [68]. Subscale scores range between 0 and 100; higher scores indicate more unfavorable situations. The reliability and unidimensionality of all scales of the VBBA were considered satisfactory [68]. Reference data were obtained from a Dutch reference sample of healthy workers [41].

The work physical demand category was assessed by the researcher according to the Dictionary of Occupational Titles (DOT). Within the DOT, occupations are classified into 5 categories of physical workload, based on intensity and duration of lifting or carrying needed for the job: sedentary, light, medium, heavy, very heavy [69].

Self reported physical work load was assessed with the Dutch Musculoskeletal Questionnaire (Dutch abbreviation: VBA; 21 items) [70]. Exposure to carrying, lifting, bending, reaching, turning, use of forces, repetitive tasks, and prolonged (inconvenient) postures is measured, reflected in a sum score ranging from 21 to 84 . Higher scores reflect a higher physical workload. Reference data were obtained from a Dutch reference sample of healthy workers [41].

\section{Statistical Analysis}

All statistical analyses were performed using SPSS for Windows, version 18.0.3. Missing data in questionnaires were addressed by adding the calculated average of a scale or questionnaire, conform questionnaire recommendations. To create a "profile" of the SAW group, the two groups were first compared on the basis of demographic, physical, psychological and work characteristics. Group differences between the SAW group and SL-Rehab group were analyzed by independent samples $T$ tests (continuous measure and normally distributed), or Mann-Whitney $U$ tests and Chi-square tests (data not distributed normally). Cohen's d effect sizes (ES) were calculated to assess the clinical relevance of differences. ES was defined as the difference between two mean scores expressed in standard deviation (sd) units: $\left(\mathrm{x}_{1}-\mathrm{x}_{2}\right) / \sigma_{\text {pooled }}$, where $\sigma_{\text {pooled }}=\sqrt{ }\left(\mathrm{sd}_{1}^{2}+\mathrm{sd}_{2}^{2} / 2\right)$. When comparing group averages, an ES $<0.2$ was 
considered as trivial, from 0.2 to 0.49 as small, from 0.5 to 0.79 as medium, and $\geq 0.8$ as large [71]. We considered an ES $\geq 0.5$ as clinically relevant $[71,72]$.

To test the hypotheses, logistic regression analyses were performed to analyze the contribution of the variables to the dependent variable group status, while controlling for potential confounding variables such as age [73], gender [74], educational level [75, 76], diagnose group, duration of pain, pain intensity [77, 78], and DOT category [69]. Because of the large number of 10 variables, the Bonferroni correction could have been applied to reduce the chance on type-I error, resulting in a $P$-value of 0.005 $(0.05 / 10$ variables $)$, which would have reduced the number of variables significantly associated with group status. However, to reduce the chance on type-II errors, we decided not to use the Bonferroni correction.

Stepwise backwards logistic regression was used to assess which of the variables best predicted group status. Based on previous research and theory we selected candidate predictors for group status and entered these in the model. We used a preselected significance value $P<0.10$ as a criterion for removal from the backwards stepwise analysis to reduce the chance of type-II errors [79]. The Hosmer and Lemeshow test was used to assess how well the chosen model fits the data. To evaluate the ability of the model to discriminate between workers in the SAW and SL-Rehab group, the area under the receiver operating characteristic curve (AUC) was calculated. An AUC of 0.50 indicates no, $0.70-0.80$ acceptable, and $>0.80$ excellent discrimination [79].

\section{Results}

A total of 119 participants were included in the SAW group and 122 in the SL-Rehab group; total sample size was 241. Seven potential participants in the SAW group were not included in the study because of heart disease (2), high blood pressure (2), neurological disorder (1), radiculopathy (1) and co-morbidity (1). Various potential participants registered for the study, but were not allowed to participate because of age $>60$ years (20), specific medical cause such as rheumatoid arthritis (48), unpaid job (11), employment less than $20 \mathrm{~h}$ (14), or more than 5\% sick leave (15).

\section{Description of SAW and SL-Rehab Group}

Demographic, physical, psychological and work characteristics of both groups are presented in Table 1. In Fig. 1 the average scores of the SAW group and SL-Rehab group are presented, supplemented with norm scores from healthy controls. To allow presentation of all variables simultaneously, all scores were transformed to a score ranging from 0 to 100 , where higher scores represent a more favorable situation. Transformed scores were only used for Fig. 1 and not in the statistical analyses. In the demographic characteristics category, compared to the SLRehab group, people in the SAW group had higher age and educational level, longer duration of pain and lower use of pain medication. Major differences between both groups were observed on physical characteristics, such as perceived pain and disability, physical functioning and physical role limitations. Moreover, workers in the SL-Rehab group perceive more pain, mental and social limitations, and score detrimental on most psychological measures. Both groups scored similar on work characteristics such as work pace, emotional load at work, relation with colleagues and supervisor, work satisfaction and need for recovery, but workers in the SAW group reported lower physical activity at work and perceived lower physical workload, which was consistent with the higher percentage of subjects working in a higher DOT-category in the SL-Rehab group.

The largest differences with the healthy controls were found in the physical characteristics category; scores in the psychological and work categories are generally similar with the SAW group.

\section{Hypotheses Tested}

In Table 2 the results of the hypothesis testing are presented. In six variables a significant association with group status was observed: fear avoidance beliefs about physical activity (OR $0.94, P=0.028$ ), pain catastrophizing (OR $0.93, P=0.005$ ), pain acceptance (OR $1.11, P=0.001$ ), pain self-efficacy (OR 1.09, $P=0.001$ ), life control (OR 1.62, $P=0.012$ ), and perceived physical workload (OR $0.93, P=0.003$ ), even after adjusting for potential confounders. Psychological distress was almost significantly associated with group status. No association with group status was observed for activity level, active coping and work satisfaction.

\section{Discriminating Between SAW and SL-Rehab Group}

In Table 3 the results of the backwards stepwise logistic regression analysis are presented. Within this regression model, group status was best discriminated by pain intensity, duration of pain, pain acceptance, perceived workload, mental health, and psychological distress. The Hosmer and Lemeshow test supported our model $\left(\chi^{2}=6.80\right.$, $P=0.56)$. The model showed excellent ability to discriminate between the SAW and SL-Rehab group (AUC $=0.91,95 \% \mathrm{CI}=0.87-0.95$ ). If the value of the pain intensity scale raises one unit (scale 0-10), the odds of a person to be in the SAW group decrease 1.8 times. When 
Table 1 Description of demographic, physical, psychological and work characteristics of the SAW and SL-Rehab group

\begin{tabular}{|c|c|c|c|c|c|c|}
\hline Instrument & Unit or scale & $\begin{array}{l}\text { SAW }(\mathrm{n}=119) \\
\text { Mean }(\mathrm{sd})\end{array}$ & $\begin{array}{l}\text { SL-Rehab }(\mathrm{n}=122) \\
\text { Mean }(\mathrm{sd})\end{array}$ & $\mathrm{n}$ & Effect size & $P$-value \\
\hline \multicolumn{7}{|l|}{ Demographic characteristics } \\
\hline Age & Years & $51(44-54)$ & $39(32-48)$ & 122 & & $0.001^{\mathrm{r}}$ \\
\hline Gender male & $\%$ & 40.3 & 46.0 & 122 & & $0.380^{\mathrm{q}}$ \\
\hline Married/co-habitation & $\%$ & 90 & 72 & 122 & & $0.001^{\mathrm{q}}$ \\
\hline Educational level & $\%$ & & & 106 & & $0.001^{\mathrm{q}}$ \\
\hline Low & & 11 & 30 & & & \\
\hline Medium & & 56 & 49 & & & \\
\hline High & & 33 & 21 & & & \\
\hline Diagnosis region & $\%$ & & & 122 & & $0.006^{\mathrm{q}}$ \\
\hline Back & & 53 & 66 & & & \\
\hline Neck/shoulders & & 13 & 18 & & & \\
\hline Fibromyalgia & & 23 & 7 & & & \\
\hline Other ${ }^{\mathrm{a}}$ & & 11 & 9 & & & \\
\hline Duration of pain & $\%$ & & & 96 & & $0.001^{\mathrm{q}}$ \\
\hline $1-2$ years & & 8.4 & 34.4 & & & \\
\hline $2-5$ years & & 10.9 & 17.8 & & & \\
\hline$>5$ years & & 80.7 & 47.8 & & & \\
\hline Pain medication (yes) & $\%$ & 39.5 & 85.1 & 73 & & $0.001^{\mathrm{q}}$ \\
\hline Frequency use pain medication & $\%$ & & & 51 & & $0.001^{\mathrm{q}}$ \\
\hline$\leq 3 /$ month & & 65 & 10 & & & \\
\hline $1-6 /$ week & & 21 & 13 & & & \\
\hline$\geq 1 /$ day & & 14 & 77 & & & \\
\hline \multicolumn{7}{|l|}{ Physical characteristics } \\
\hline NRS current pain ${ }^{\mathrm{b}}$ & $0-10$ & $4.6(2.1)$ & $6.1(1.9)$ & 114 & 0.8 & 0.001 \\
\hline NRS worst pain & $0-10$ & $6.9(1.8)$ & $8.0(1.4)$ & 88 & 0.7 & 0.001 \\
\hline $\mathrm{PDI}^{\mathrm{c}}$ & $0-70$ & $19.9(11.1)$ & $39.2(11.2)$ & 92 & 1.7 & 0.001 \\
\hline \multicolumn{7}{|l|}{ RAND $36^{\mathrm{d}}$} \\
\hline Physical functioning & $0-100$ & $72.8(17.9)$ & $48.0(19.8)$ & & 1.3 & 0.001 \\
\hline Role limitations (physical) & $0-100$ & $50(0-100)$ & $0(0-0)$ & 93 & 1.2 & $0.001^{\mathrm{r}}$ \\
\hline Pain & $0-100$ & $55.4(15.5)$ & $36.6(17.0)$ & 93 & 1.2 & 0.001 \\
\hline General health perception & $0-100$ & $62.9(17.7)$ & $58.2(18.9)$ & 93 & 0.3 & 0.072 \\
\hline Health changes & $0-100$ & $46.6(18.7)$ & $32.8(24.8)$ & 93 & 0.6 & 0.001 \\
\hline Physical component summary & $0-100$ & $59.8(17.0)$ & $38.5(12.7)$ & 93 & 1.4 & 0.001 \\
\hline \multicolumn{7}{|l|}{$\mathrm{BPAQ}^{\mathrm{e}}$} \\
\hline Work & $1-5$ & $2.7(0.6)$ & $3.2(0.6)$ & 116 & 0.8 & 0.001 \\
\hline Sport & $1-5$ & $2.6(0.8)$ & $2.3(0.6)$ & 118 & 0.4 & 0.004 \\
\hline Leisure time & $1-5$ & $3.1(0.6)$ & $3.0(0.6)$ & 118 & 0.2 & 0.108 \\
\hline Total activity level & $3-15$ & $8.4(1.2)$ & $8.5(1.1)$ & 116 & 0.1 & 0.625 \\
\hline \multicolumn{7}{|l|}{ Psychological characteristics } \\
\hline \multicolumn{7}{|l|}{ RAND $36^{\mathrm{d}}$} \\
\hline Social functioning & $0-100$ & $78.7(18.8)$ & $56.2(24.3)$ & 93 & 1.0 & 0.001 \\
\hline Role limitations (emotional) & $0-100$ & $100(100-100)$ & $67(0-100)$ & 93 & 0.8 & $0.001^{\mathrm{r}}$ \\
\hline Mental health & $0-100$ & $75.4(16.4)$ & $63.6(16.2)$ & 93 & 0.7 & 0.001 \\
\hline Vitality & $0-100$ & $58.1(18.3)$ & $43.9(16.9)$ & 93 & 0.8 & 0.001 \\
\hline Mental component summary & $0-100$ & $74.1(17.0)$ & $54.6(20.2)$ & 93 & 1.0 & 0.001 \\
\hline \multicolumn{7}{|l|}{ SCL90-R ${ }^{\mathrm{f}}$} \\
\hline Anxiety & $10-50$ & $12(10-14)$ & $14(12-17)$ & 108 & 0.5 & $0.001^{\mathrm{r}}$ \\
\hline
\end{tabular}


Table 1 continued

\begin{tabular}{|c|c|c|c|c|c|c|}
\hline Instrument & Unit or scale & $\begin{array}{l}\text { SAW }(\mathrm{n}=119) \\
\text { Mean }(\mathrm{sd})\end{array}$ & $\begin{array}{l}\text { SL-Rehab }(\mathrm{n}=122) \\
\text { Mean }(\mathrm{sd})\end{array}$ & $\mathrm{n}$ & Effect size & $P$-value \\
\hline Phobic anxiety & $7-35$ & $7(7-8)$ & $7(7-9)$ & 108 & 0.4 & $0.050^{\mathrm{r}}$ \\
\hline Depression & $16-80$ & $20(17-25)$ & $26(21-35)$ & 108 & 0.6 & $0.001^{\mathrm{r}}$ \\
\hline Somatization & $12-60$ & $20.9(5.7)$ & $25.5(6.3)$ & 108 & 0.8 & 0.001 \\
\hline Obsessive-compulsive & $9-45$ & $14.8(4.3)$ & $20.8(11.3)$ & 108 & 0.7 & 0.001 \\
\hline Interpersonal sensitivity & $18-90$ & $22(19-28)$ & $24(20-31)$ & 108 & 0.2 & $0.189^{r}$ \\
\hline Hostility & $6-30$ & $7(6-7)$ & $8(7-9)$ & 108 & 0.6 & $0.001^{\mathrm{r}}$ \\
\hline Sleep disturbance & $3-15$ & $5(4-7)$ & $7(5-11)$ & 108 & 0.5 & $0.001^{\mathrm{r}}$ \\
\hline Psychoticism & $9-45$ & $10(9-12)$ & $12(10-14)$ & 108 & 0.4 & $0.003^{r}$ \\
\hline Global severity index & $90-450$ & $118(105-141)$ & $142(123-177)$ & 108 & 0.7 & $0.001^{\mathrm{r}}$ \\
\hline \multicolumn{7}{|l|}{$\mathrm{CPAQ}^{\mathrm{g}}$} \\
\hline Activity engagement & $0-66$ & $43.5(7.2)$ & $34.6(9.6)$ & 118 & 1.0 & 0.001 \\
\hline Pain willingness & $0-54$ & $28.7(7.5)$ & $21.4(7.1)$ & 118 & 1.0 & 0.001 \\
\hline Total score & $0-120$ & $72.2(11.7)$ & $56.4(13.1)$ & 118 & 1.3 & 0.001 \\
\hline $\mathrm{TSK}^{\mathrm{h}}$ & $17-68$ & $33.0(7.2)$ & $37.2(8.1)$ & 107 & 0.5 & 0.001 \\
\hline PSEQ self efficacy ${ }^{\mathrm{i}}$ & $0-60$ & $46.9(8.5)$ & $35.5(12.0)$ & 121 & 1.1 & 0.001 \\
\hline $\mathrm{PCS}^{\mathrm{j}}$ & $0-52$ & $10.5(8.6)$ & $21.6(10.4)$ & 77 & 1.2 & 0.001 \\
\hline Rumination & $0-16$ & $4.7(3.6)$ & $8.2(3.9)$ & 77 & 0.9 & 0.001 \\
\hline Magnification & $0-12$ & $1.2(1.6)$ & $3.1(2.4)$ & 77 & 0.9 & 0.001 \\
\hline Helplessness & $0-24$ & $4.5(4.1)$ & $10.1(4.8)$ & 77 & 1.3 & 0.001 \\
\hline \multicolumn{7}{|l|}{$\mathrm{UCL}^{\mathrm{k}}$} \\
\hline Active coping & $7-28$ & $19.3(3.4)$ & $17.7(3.4)$ & 109 & 0.5 & 0.001 \\
\hline Palliative reaction & $8-32$ & $17.7(3.4)$ & $17.6(3.7)$ & 109 & 0.0 & 0.768 \\
\hline Avoidance & $8-32$ & $16.2(3.4)$ & $15.8(3.2)$ & 109 & 0.1 & 0.305 \\
\hline Social support & $6-24$ & $13.1(3.6)$ & $12.8(3.4)$ & 109 & 0.1 & 0.508 \\
\hline Passive coping & $7-28$ & $10.9(3.0)$ & $12.0(3.1)$ & 109 & 0.4 & 0.012 \\
\hline Expression of emotions & $3-12$ & $5.7(1.5)$ & $5.3(1.6)$ & 109 & 0.3 & 0.049 \\
\hline Coping self statements & $5-20$ & $12.6(2.7)$ & $11.9(2.6)$ & 109 & 0.3 & 0.042 \\
\hline \multicolumn{7}{|l|}{ MPI $^{1}$} \\
\hline Life control & $0-6$ & $5.0(4.7-5.7)$ & $4.0(3.0-5.0)$ & 119 & 0.9 & $0.001^{\mathrm{r}}$ \\
\hline Mood & $0-6$ & $4.7(3.7-5.3)$ & $3.7(2.7-5.0)$ & 120 & 0.6 & $0.001^{\mathrm{r}}$ \\
\hline Support & $0-6$ & $4.0(3.0-4.9)$ & $5.0(4.0-5.3)$ & 100 & 0.6 & $0.001^{\mathrm{r}}$ \\
\hline Punishing responses & $0-6$ & $1.0(0.3-1.7)$ & $1.3(0.3-2.7)$ & 100 & 0.3 & $0.029^{r}$ \\
\hline Solicitous responses & $0-6$ & $2.3(1.1)$ & $2.8(1.0)$ & 100 & 0.5 & 0.001 \\
\hline Distracting responses & $0-6$ & $2.4(1.4)$ & $2.9(1.2)$ & 99 & 0.4 & 0.012 \\
\hline \multicolumn{7}{|l|}{ Work characteristics } \\
\hline Expected to work last week & Hours & $31.5(7.8)$ & $35.0(11.1)$ & 122 & 0.4 & 0.007 \\
\hline Actually worked last week & Hours & $32.5(10.4)$ & $11.3(13.8)$ & 113 & 1.7 & 0.001 \\
\hline HPQ presenteeism ${ }^{\mathrm{m}}$ & $0-100$ & $76.9(11.1)$ & $46.7(29.5)$ & 89 & 1.4 & 0.001 \\
\hline HPQ relative presenteeism & $0.25-2$ & $1.1(0.3)$ & $0.75(0.4)$ & 85 & 1.0 & 0.001 \\
\hline Employment & $\%$ & & & 114 & & $0.260^{\mathrm{q}}$ \\
\hline Part-time & & 49.6 & 42.2 & & & \\
\hline Full-time & & 50.4 & 57.8 & & & \\
\hline Sick leave & $\%$ & & & 122 & & $0.001^{\mathrm{q}}$ \\
\hline$<5 \%$ & & 100 & 0 & & & \\
\hline $5-20 \%$ & & 0 & 16.5 & & & \\
\hline $21-50 \%$ & & 0 & 20 & & & \\
\hline$>50 \%$ & & 0 & 63.5 & & & \\
\hline
\end{tabular}


Table 1 continued

\begin{tabular}{|c|c|c|c|c|c|c|}
\hline Instrument & Unit or scale & $\begin{array}{l}\text { SAW }(n=119) \\
\text { Mean }(s d)\end{array}$ & $\begin{array}{l}\text { SL-Rehab }(n=122) \\
\text { Mean }(\mathrm{sd})\end{array}$ & $\mathrm{n}$ & Effect size & $P$-value \\
\hline Vocational sector & $\%$ & & & 115 & & \\
\hline Industry & & 8 & 13 & & & \\
\hline Construction & & 1 & 8 & & & \\
\hline Trade & & 9 & 18 & & & \\
\hline Transport & & 4 & 5 & & & \\
\hline Commercial services & & 9 & 7 & & & \\
\hline Education & & 13 & 7 & & & \\
\hline Health care & & 34 & 25 & & & \\
\hline Public administration & & 13 & 7 & & & \\
\hline Agriculture & & 4 & 4 & & & \\
\hline Other & & 5 & 6 & & & \\
\hline \multicolumn{7}{|l|}{ Work demands } \\
\hline Physical demand category work & & & & 122 & & $0.007^{\mathrm{q}}$ \\
\hline DOT category $1^{\mathrm{n}}$ & $\%$ & 35 & 20 & & & \\
\hline DOT category 2 & $\%$ & 35 & 33 & & & \\
\hline DOT category 3 & $\%$ & 24 & 29 & & & \\
\hline DOT category 4 & $\%$ & 6 & 18 & & & \\
\hline \multicolumn{7}{|l|}{$\mathrm{VBBA}^{\circ}$} \\
\hline Work pace & $0-100$ & $41.3(13.9)$ & $45.8(15.2)$ & 111 & 0.3 & 0.023 \\
\hline Emotional load & $0-100$ & $31.9(15.1)$ & $25.8(15.1)$ & 111 & 0.4 & 0.003 \\
\hline Relation with colleagues & $0-100$ & $0(0-11)$ & $0(0-11)$ & 109 & 0.0 & $0.560^{\mathrm{r}}$ \\
\hline Relation with supervisor & $0-100$ & $0(0-11)$ & $0(0-11)$ & 106 & 0.1 & $0.710^{\mathrm{r}}$ \\
\hline Work satisfaction & $0-100$ & $0(0-11)$ & $0(0-22)$ & 110 & 0.3 & $0.024^{\mathrm{r}}$ \\
\hline Need for recovery & $0-100$ & $45(18-73)$ & $64(18-82)$ & 109 & 0.3 & $0.020^{\mathrm{r}}$ \\
\hline $\mathrm{VBA}^{\mathrm{p}}$ & $21-84$ & $43.1(10.4)$ & $52.5(12.3)$ & 112 & 0.8 & 0.001 \\
\hline
\end{tabular}

${ }^{a}$ Pain of extremity, cervical-brachial syndrome, generalized pain, ${ }^{\mathrm{b}}$ Numeric Rating Scale $\left(0=\right.$ no pain, $10=$ worst possible pain), ${ }^{\mathrm{c}}$ Pain Disability Index, ${ }^{\mathrm{d}}$ RAND 36-item Health Survey, ${ }^{\mathrm{e}}$ Baecke Physical Activity Questionnaire, ${ }^{\mathrm{f}}$ Symptom Checklist $90-\mathrm{R}$, ${ }^{\mathrm{g}}$ Chronic Pain Acceptance Questionnaire, ${ }^{\mathrm{h}}$ Tampa Scale for Kinesiophobia, ${ }^{\mathrm{i}}$ Pain Self Efficacy Questionnaire, ${ }^{\mathrm{j}}$ Pain Catastrophizing Scale, ${ }^{\mathrm{k}}$ Utrecht's Coping List, ${ }^{1}$ Multidimensional Pain Inventory, ${ }^{\mathrm{m}}$ Health and Work Performance Questionnaire, ${ }^{\mathrm{n}}$ Dictionary of Occupational Titles; $1=$ sedentary; 2 = light; $3=$ medium; 4 = heavy/very heavy work, ${ }^{\circ}$ Questionnaire on the Perception and Evaluation of Work, ${ }^{\mathrm{p}}$ Dutch Musculoskeletal Questionnaire, ${ }^{\mathrm{q}}$ Chi-squared test $\left(\chi^{2}\right.$-test), ${ }^{\mathrm{r}}$ Mann-Whitney $U$ test, outlined in the table with median $(25-75 \%$ inter-quartile range)

pain duration is longer than 5 years, the odds to be in the SAW group increase 6.4 times. A higher score of one unit on pain acceptance (scale 0-120), mental health (scale 0-100) or psychological distress (scale 90-450) increased the odds to stay at work (OR 1.08, 1.07 and 1.02), while a higher score of one unit on perceived workload (scale 21-84) reduced the odds to stay at work (OR 1.10).

\section{Discussion}

\section{Main Findings}

The aim of this study was to describe and compare the differences of a SAW group and a SL-Rehab group on physical, psychological and work characteristics. An extended profile of this relative unknown SAW group was presented (Table 1) and a crude comparison with the SL-Rehab group and healthy controls was made (Table 1, Fig. 1). Based on theoretical grounds we hypothesized to identify several differences between the SAW and SL-Rehab group. Significant differences were found for fear avoidance, pain catastrophizing, pain acceptance, pain self-efficacy beliefs, life control and perceived physical workload. The SAW and SL-Rehab group scored similar on activity level, active coping and work satisfaction. Both groups were best discriminated by pain intensity, pain duration, pain acceptance, mental health, psychological distress and perceived workload.

Contrary to the present study, in a systematic review on factors promoting staying at work in workers with CMP, pain catastrophizing was consistently not associated with 
Fig. 1 A comparison of the SAW group, SL-Rehab group, and healthy working controls. The y-axis represents transformed scores on a standardized $0-100$ scale, in which higher scores represent more favorable situations. The $\mathrm{x}$-axis shows all variables. No norm scores of healthy controls were retrieved for variables indicated with ${ }^{1}$
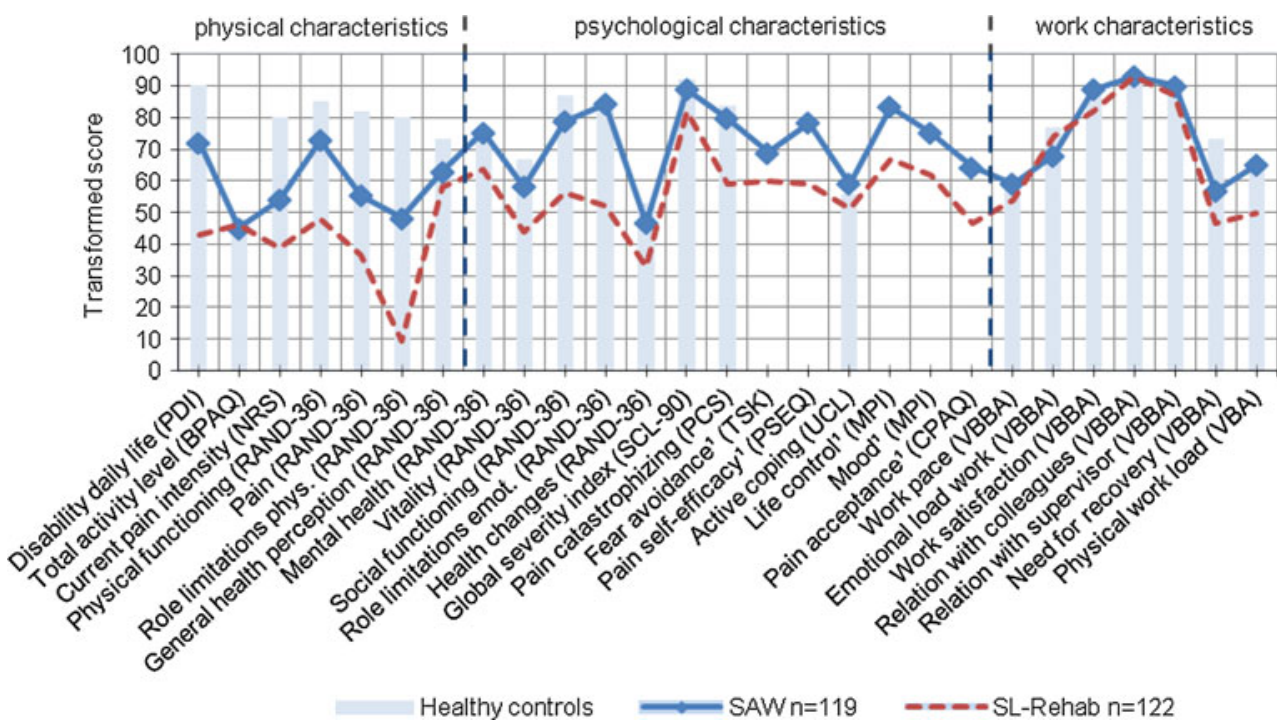

Table 2 Hypotheses $(\mathrm{H})$ tested by logistic regression, adjusted for potential confounders, with group status as dependent variable

\begin{tabular}{|c|c|c|c|c|c|c|}
\hline Instrument & Hypothesis & $\mathrm{n}$ & $\mathrm{B}$ & $P$-value & $\operatorname{Exp}(B)$ & $95 \%$ CI $\operatorname{Exp}(\mathrm{B})$ \\
\hline \multicolumn{7}{|l|}{ Physical characteristics } \\
\hline H1: Activity level ${ }^{\mathrm{a}}$ & SAW > SL-Rehab & 193 & -0.10 & 0.597 & 0.91 & {$[0.64-1.30]$} \\
\hline \multicolumn{7}{|l|}{ Psychological characteristics } \\
\hline H2: Fear avoidance ${ }^{b}$ & SAW $<$ SL-Rehab & 190 & -0.06 & $0.028 *$ & 0.94 & {$[0.90-0.99]$} \\
\hline H3: Pain catastrophizing ${ }^{\mathrm{c}}$ & SAW $<$ SL-Rehab & 165 & -0.07 & $0.005^{*}$ & 0.93 & {$[0.88-0.98]$} \\
\hline H4: Pain acceptance ${ }^{\mathrm{d}}$ & SAW > SL-Rehab & 196 & 0.10 & $0.001 *$ & 1.11 & [1.06-1.16] \\
\hline H5: Psychological distress ${ }^{\mathrm{e}}$ & SAW $<$ SL-Rehab & 190 & -0.01 & 0.082 & 0.99 & {$[0.98-1.00]$} \\
\hline H7: Pain self efficacy ${ }^{\mathrm{f}}$ & SAW > SL-Rehab & 198 & 0.09 & $0.001 *$ & 1.09 & [1.05-1.14] \\
\hline H6: Life control ${ }^{\mathrm{g}}$ & SAW $>$ SL-Rehab & 196 & 0.48 & $0.012 *$ & 1.62 & {$[1.11-2.36]$} \\
\hline H8: Active coping ${ }^{\text {h }}$ & SAW > SL-Rehab & 191 & 0.04 & 0.490 & 1.04 & {$[0.92-1.18]$} \\
\hline \multicolumn{7}{|l|}{ Work characteristics } \\
\hline H9: Work satisfaction ${ }^{\mathrm{i}}$ & SAW > SL-Rehab & 190 & -0.00 & 0.639 & 1.00 & [0.98-1.01] \\
\hline H10: Physical workload ${ }^{\mathrm{j}}$ & SAW $<$ SL-Rehab & 192 & -0.07 & $0.003 *$ & 0.93 & {$[0.89-0.98]$} \\
\hline
\end{tabular}

$\operatorname{Exp}(B)>1$ indicated a higher chance to be in the SAW group

* Significant difference, $P<0.05$

${ }^{\mathrm{a}}$ Baecke Physical Activity Questionnaire, ${ }^{\mathrm{b}}$ Tampa Scale for Kinesiophobia, ${ }^{\mathrm{c}}$ Pain Catastrophizing Scale, ${ }^{\mathrm{d}}$ Chronic Pain Acceptance Questionnaire, ${ }^{\mathrm{e}}$ Symptom Checklist R-90, ${ }^{\mathrm{f}}$ Pain Self Efficacy Questionnaire, ${ }^{\mathrm{g}}$ Multidimensional Pain Inventory, ${ }^{\mathrm{h}}$ Utrecht's Coping List, ${ }^{\mathrm{i}}$ Questionnaire on the Perception and Evaluation of Work, ${ }^{\mathrm{j}}$ Dutch Musculoskeletal Questionnaire

staying at work [22]. Although different questionnaires were used to measure pain catastrophizing, a plausible explanation for this contradictory observation is unavailable. Pain acceptance has been observed to be associated with better work status [16]. The higher level of pain acceptance experienced by workers in the SAW group means that they participated more in daily activities while acknowledging the presence of pain, and were better able to allow pain in experiences without efforts to avoid or control it. This was not conflicting with the detected higher feelings of life control in our SAW group: paradoxically, when pain control becomes less important, the feeling to have control over life increases. Some people believe that once their pain is solved, they regain the ability to fulfill their work demands. Because these people "rely on the healthcare system and still seek for a medical solution for their pain", they have decreased power of life control [80].

Workers in the SAW group reported significantly higher pain self-efficacy beliefs compared to sick-listed workers in the SL-Rehab group. Having high self-efficacy beliefs can be considered as a prerequisite for behavior promoting staying at work, such as: raising adjustment latitude, changing pain-coping strategies, organizing modifications and conditions at work, finding access to healthcare 
Table 3 Results of the logistic regression analysis, with group status as dependent variable

\begin{tabular}{|c|c|c|c|c|c|}
\hline Predictor & $\mathrm{B}$ & SE & $P$-value & $\operatorname{Exp}(B)$ & $95 \%$ CI $\operatorname{Exp}(B)$ \\
\hline \multicolumn{6}{|l|}{ Physical characteristics } \\
\hline Pain intensity ( 1 point higher) & -0.61 & 0.17 & 0.001 & 0.55 & {$[0.39-0.76]$} \\
\hline Pain duration ( $>5$ years) & 1.86 & 0.68 & 0.006 & 6.40 & {$[1.70-24.00]$} \\
\hline \multicolumn{6}{|l|}{ Psychological characteristics } \\
\hline Pain acceptance (1 point higher) & 0.08 & 0.02 & 0.002 & 1.08 & [1.03-1.14] \\
\hline Mental health (1 point higher) & 0.07 & 0.02 & 0.001 & 1.07 & [1.03-1.12] \\
\hline Psychological distress (1 point higher) & 0.02 & 0.01 & 0.036 & 1.02 & {$[1.00-1.04]$} \\
\hline \multicolumn{6}{|l|}{ Work characteristics } \\
\hline Perceived workload (1 point higher) & -0.10 & 0.03 & 0.002 & 0.91 & [0.85-0.97] \\
\hline
\end{tabular}

$\operatorname{Exp}(\mathrm{B})>1$ indicated a higher chance to be in the SAW group

$\chi^{2}=82.9($ degrees of freedom $=6, \mathrm{n}=151), P<0.001$

services, and asking for support [21,81]. Many patients with CMP have resistance to behavioral changes or a lack of self-management skills to make that change. Vocational rehabilitation to promote staying at work in people with CMP should consider to target pain self-efficacy.

A systematic review on factors promoting staying at work in people with CMP concluded that low perceived physical disability and low emotional distress were associated with staying at work [22]. This was confirmed in the present study, where large differences were observed on these variables between the groups. Because we selected two groups based on work status and rehabilitation status, it was not surprising that the groups differed on perceived disability. It was also expected that the groups would differ on activity level, however, no difference was observed. The considerable difference on perceived disability between the two groups, while having the same activity level, is remarkable. Even compared with healthy working controls the activity level of workers with CMP, whether sick listed or not, did not differ. This result does not support the assumption of activating to promote returning to work, or activating sports at work for remaining at work, which is often postulated in literature [82, 83]. Simply activating patients with CMP in rehabilitation programs to promote sustained work participation or return to work may be reconsidered, because the working mechanism is unknown, and it may be only effective for subgroups [84]. Coping strategy was not associated with group status. In an interview study on staying at work, participants judged their coping style as an important success factor to stay at work. It appeared that opposite coping strategies (e.g., medication use can be viewed both as an active and a passive coping strategy) could lead to the similar results [81].

People in the SAW group were on average almost 10 years older. This might be the consequence of the selection process; participation into the study was probably more attractive for older people. In addition, the "healthy worker" effect may have resulted in younger workers admitted for rehabilitation, reducing the age in the SL-Rehab group. Older workers, who often had longer duration of pain, may have had more time to re-organize their lives and probably better learned to accept the pain. In another study was observed that older persons were less likely to be out off work due to pain [16] and a few studies observed that age was not associated with staying at work [85-87].

Work factors are frequently associated with sick-leave and work disability [13, 88, 89]. In our study physical factors at work, such as perceived physical workload, were stronger associated with staying at work than psycho-social factors, which is consistent with other research [90]. Workers with strenuous jobs may sooner experience problems to stay at work with CMP. Vocational rehabilitation should improve the functional capacity of these workers, or investigate possibilities for workplace adjustments.

\section{Discriminating Between SAW and SL-Rehab Group}

In the stepwise logistic regression model, being in the SAW group was best predicted by lower pain intensity, longer duration of pain, better pain acceptance, lower perceived physical workload, better mental health, and more psychological distress. Contrary to expectations based on the univariate analyses, higher psychological distress was (minimally) associated with being in the SAW group. In all the three domains of physical-, psychologicaland work characteristics were variables that contributed to distinguish both groups, suggesting that factors from multiple domains are important for sustained work participation. Future research concerning disability prevention may target these variables that may be promising for sustained work participation. Pain related variables were strongly associated with group status, suggesting that pain intensity 
matters in sustained work participation. The SAW group reported on average 1.5 points less pain compared to the SL-Rehab group, which was a significant difference, but not clinically relevant $[35,91,92]$. In our study pain intensity was one of the variables that explained group membership. We do not know whether pain reduction would be effective to improve workability. Some studies concluded that disability level rises gradually with pain intensity [78, 93-95]. In other studies pain intensity was not observed as a significant predictor for work ability [16, $20,85]$. Whether pain reduction should be a target in multidisciplinary rehabilitation for CMP to improve workability is under debate. Nevertheless, workers in the SAW group have shown that sustained work participation with CMP is indeed possible.

\section{Strengths and Limitations of the Study}

The current study is the first that provides a profile of workers with CMP who succeed to stay at work despite pain, which complemented our view on work participation in CMP and may contribute to a better understanding of work participation in non-clinical samples. People who stay at work are less accessible for research, yet we managed to include 119 participants. When group size is large, differences between groups turn out to be significant very soon, sometimes even when differences are negligible. We expressed the magnitude of the differences in ES to elevate the robustness of the results. All participants in our study were physically examined and medical data were available, so diagnoses were not solely based on self-report.

A few limitations in our study need careful attention. Participants in the SAW group responded to a call in a newspaper in which they were invited to take part in the study. In this design selection bias is inevitable and diminishes the external validity of the results. Higher educated or older workers may have been more prone to participate into the study and workers with high decision latitude had better opportunity to leave their job for a few hours and participate into the study. In our analysis we adjusted for educational level and other potential confounding variables. In this explorative study, data of the SAW and SL-Rehab group was collected at one point in time. Because of the cross-sectional data collection, no causal inferences could be made. Secondly, workers who managed to stay at work may have become sick-listed after participating into our study, thus violate the SAW condition we defined. We included workers without sick-leave during the past 12 months due to CMP. Most participants had positive expectations to remain at work the next 2 years, $20 \%$ was unsure and $1 \%$ did not expect to work after 2 years. Therefore, we considered it was not likely that many workers in the SAW group became sick-listed soon after participation into our study. We investigated workers with CMP, which was not defined as a uniform diagnosis group, and therefore might influence interpretation of data. We made this choice because in daily practice clinicians are confronted with patients who present a diversity of diagnoses with often more than one pain site [5, 96, 97]. In testing our hypotheses we controlled for diagnose group, which did not alter the results.

This study was conducted in The Netherlands. In other societies or cultures, with different compensation systems for work disability, determinants for sustained work participation may be different [98]. Our study was explorative and may be used to direct future research and clinical developments in vocational rehabilitation and sustained work participation of workers with CMP. Clinicians may use the characteristics of the SAW and SL-Rehab group to estimate the relevance of "deviant" scores of their patients. Longitudinal studies on SAW are needed to further increase our knowledge about staying at work with CMP.

\section{Conclusions}

A wide range of bio-psycho-social characteristics of workers who stay at work despite CMP were explored. People who stay at work despite pain have clinically relevant different scores compared to sick-listed workers with CMP referred for multidisciplinary rehabilitation on fear avoidance beliefs about physical activity, pain catastrophizing, pain acceptance, pain self efficacy, life control and perceived physical workload. Group status was not associated with activity level, coping strategy and work satisfaction. The SAW and SL-Rehab group could be discriminated the best by pain intensity, duration of pain, pain acceptance, perceived physical workload, mental health, and psychological distress. Further research on these topics is needed to raise our understanding of staying at work despite CMP and to investigate the usefulness for sustained work participation.

Acknowledgments We wish to thank Ilse Stuive and Michiel de Boer for their support in the statistical analysis. This study was funded by Stichting Instituut Gak, Grant Number 2006479.

Conflict of interest The authors declare that they have no conflict of interest.

Open Access This article is distributed under the terms of the Creative Commons Attribution License which permits any use, distribution, and reproduction in any medium, provided the original author(s) and the source are credited. 


\section{References}

1. Henriksson CM, Liedberg GM, Gerdle B. Women with fibromyalgia: work and rehabilitation. Disabil Rehabil. 2005; 27(12):685-94.

2. Breivik H, Collett B, Ventafridda V, Cohen R, Gallacher D. Survey of chronic pain in Europe: prevalence, impact on daily life, and treatment. Eur J Pain. 2006;10(4):287-333.

3. Waddell G, Burton AK. Is work good for your health and wellbeing?. London: TSO; 2006.

4. Zitman FG, Linssen AC, Van HR. Chronic pain beyond patienthood. J Nerv Ment Dis. 1992;180(2):97-100.

5. Picavet HS, Schouten JS. Musculoskeletal pain in the Netherlands: prevalences, consequences and risk groups, the $\mathrm{DMC}(3)$ study. Pain. 2003;102(1-2):167-78.

6. IJzelenberg W, Burdorf A. Patterns of care for low back pain in a working population. Spine (Phila Pa 1976). 2004;29(12): 1362-1368.

7. Truchon M, Fillion L. Biopsychosocial determinants of chronic disability and low-back pain: a review. J Occup Rehabil. 2000;10(2):117-42.

8. Krause N, Frank JW, Dasinger LK, Sullivan TJ, Sinclair SJ. Determinants of duration of disability and return-to-work after work-related injury and illness: challenges for future research. Am J Ind Med. 2001;40(4):464-84.

9. Werner EL, Cote P. Low back pain and determinants of sickness absence. Eur J Gen Pract. 2009;15(2):74-9.

10. Vlaeyen JW, Linton SJ. Fear-avoidance and its consequences in chronic musculoskeletal pain: a state of the art. Pain. 2000; 85(3):317-32.

11. Leeuw M, Goossens ME, Linton SJ, Crombez G, Boersma K, Vlaeyen JW. The fear-avoidance model of musculoskeletal pain: current state of scientific evidence. J Behav Med. 2007;30(1): 77-94.

12. Severeijns R, Vlaeyen JW, van den Hout MA, Weber WE. Pain catastrophizing predicts pain intensity, disability, and psychological distress independent of the level of physical impairment. Clin J Pain. 2001;17(2):165-72.

13. Sullivan MJ, Feuerstein M, Gatchel R, Linton SJ, Pransky G. Integrating psychosocial and behavioral interventions to achieve optimal rehabilitation outcomes. J Occup Rehabil. 2005;15(4): 475-89.

14. Verbunt JA, Seelen HA, Vlaeyen JW, van de Heijden GJ, Heuts $\mathrm{PH}$, Pons K, et al. Disuse and deconditioning in chronic low back pain: concepts and hypotheses on contributing mechanisms. Eur J Pain. 2003;7(1):9-21.

15. Brox JI, Storheim K, Holm I, Friis A, Reikeras O. Disability, pain, psychological factors and physical performance in healthy controls, patients with sub-acute and chronic low back pain: a case-control study. J Rehabil Med. 2005;37(2):95-9.

16. McCracken LM. Learning to live with the pain: acceptance of pain predicts adjustment in persons with chronic pain. Pain. 1998;74(1):21-7.

17. Vowles KE, McCracken LM. Acceptance and values-based action in chronic pain: a study of treatment effectiveness and process. J Consult Clin Psychol. 2008;76(3):397-407.

18. Walker EA, Keegan D, Gardner G, Sullivan M, Bernstein D, Katon WJ. Psychosocial factors in fibromyalgia compared with rheumatoid arthritis: II. Sexual, physical, and emotional abuse and neglect. Psychosom Med. 1997;59(6):572-577.

19. Haugli L, Steen E, Laerum E, Nygård R, Finset A. Psychological distress and employment status: effects of a group learning programme for patients with chronic musculoskeletal pain. Psychol Health Med. 2003;8(2):135-48.
20. Denison E, Asenlof P, Lindberg P. Self-efficacy, fear avoidance, and pain intensity as predictors of disability in subacute and chronic musculoskeletal pain patients in primary health care. Pain. 2004;111(3):245-52.

21. Brouwer S, Krol B, Reneman MF, Bultmann U, Franche RL, van der Klink JJ, et al. Behavioral determinants as predictors of return to work after long-term sickness absence: an application of the theory of planned behavior. J Occup Rehabil. 2009;19(2):166-74.

22. de Vries HJ, Reneman MF, Groothoff JW, Geertzen JH, Brouwer S. Factors promoting staying at work in people with chronic nonspecific musculoskeletal pain: a systematic review. Disabil Rehabil. 2012;34(6):443-458.

23. Shaw WS, Linton SJ, Pransky G. Reducing sickness absence from work due to low back pain: how well do intervention strategies match modifiable risk factors? J Occup Rehabil. 2006;16(4):591-605.

24. Vowles KE, Gross RT, Sorrell JT. Predicting work status following interdisciplinary treatment for chronic pain. Eur J Pain. 2004;8(4):351-8.

25. Gulick EE. Model for predicting work performance among persons with multiple sclerosis. Nurs Res. 1992;41(5):266-72.

26. Bandura A. Self-efficacy: toward a unifying theory of behavioral change. Psychol Rev. 1977;84(2):191-215.

27. Lackner JM, Carosella AM. The relative influence of perceived pain control, anxiety, and functional self efficacy on spinal function among patients with chronic low back pain. Spine (Phila Pa 1976). 1999;24(21):2254-60; discussion 2260-2261.

28. Nicholas MK. The pain self-efficacy questionnaire: taking pain into account. Eur J Pain. 2007;11(2):153-63.

29. Central Statistics office. Sickness absence stabilising last years. In Dutch: Centraal bureau voor statistiek. Ziekteverzuim laatste jaren stabiel. CBS-publications; 2010.

30. Livanos I. Sickness absence a Pan-European study. 2010. http:// mpra.ub.uni-muenchen.de/22627. Accessed 6 Oct 2011.

31. Escorpizo R, Reneman MF, Ekholm J, Fritz J, Krupa T, Marnetoft SU, et al. A conceptual definition of vocational rehabilitation based on the ICF: building a shared global model. J Occup Rehabil. 2011;21(2):126-33.

32. Peduzzi P, Concato J, Kemper E, Holford TR, Feinstein AR. A simulation study of the number of events per variable in logistic regression analysis. J Clin Epidemiol. 1996;49(12):1373-9.

33. Engers AJ, Koke A, Torenbeek M, editors. Nederlandse dataset pijnrevalidatie. Hoensbroek: Stichting Revalidatie Limburg, The Netherlands; 2007.

34. Jensen MP, Karoly P, Braver S. The measurement of clinical pain intensity-a comparison of 6 methods. Pain. 1986;27(1):117-26.

35. Farrar JT, Young JP, LaMoreaux L, Werth JL, Poole RM. Clinical importance of changes in chronic pain intensity measured on an 11-point numerical pain rating scale. Pain. 2001;94(2):149-58.

36. Pollard CA. Preliminary validity study of pain disability index. Percept Mot Skills. 1984;59:974.

37. Tait RC, Chibnall JT, Krause S. The pain disability index: psychometric properties. Pain. 1990;40(2):171-82.

38. Mewes R, Rief W, Stenzel N, Glaesmer H, Martin A, Brahler E. What is "normal" disability? An investigation of disability in the general population. Pain. 2009;142(1-2):36-41.

39. van der Zee KI, Sanderman R. Het meten van de algemene gezondheidstoestand met de RAND-36: Een handleiding. [Measuring general health with the RAND-36: A manual]. Groningen: Noordelijk Centrum voor Gezondheidsvraagstukken, NCG; 1993.

40. Hays RD, Morales LS. The RAND-36 measure of health-related quality of life. Ann Med. 2001;33(5):350-7.

41. Soer R, van der Schans CP, Geertzen JH, Groothoff JW, Brouwer S, Dijkstra PU, et al. Normative values for a functional capacity evaluation. Arch Phys Med Rehabil. 2009;90(10):1785-94. 
42. Baecke JA, Burema J, Frijters JE. A short questionnaire for the measurement of habitual physical activity in epidemiological studies. Am J Clin Nutr. 1982;36(5):936-42.

43. Jacobs DR Jr, Ainsworth BE, Hartman TJ, Leon AS. A simultaneous evaluation of 10 commonly used physical activity questionnaires. Med Sci Sports Exerc. 1993;25(1):81-91.

44. Bernstein IH, Jaremko ME, Hinkley BS. On the utility of the SCL-90-R with low-back pain patients. Spine (Phila Pa 1976). 1994;19(1):42-48.

45. Arrindell W, Ettema JHM. SCL-90: Handleiding bij een multidimensionale psychopathologie indicator. Lisse: Swets Test Publishers; 2003.

46. Geiser DS. A comparison of acceptence-focussed and controlfocussed psychological treatments in a chronic pain treatment center. Dissertation. University of Nevada; 1992.

47. McCracken LM, Vowles KE, Eccleston C. Acceptance of chronic pain: component analysis and a revised assessment method. Pain. 2004;107(1-2):159-66.

48. Vowles KE, McCracken LM, McLeod C, Eccleston C. The chronic pain acceptance questionnaire: confirmatory factor analysis and identification of patient subgroups. Pain. 2008;140(2): 284-91.

49. Wicksell RK, Olsson GL, Melin L. The chronic pain acceptance questionnaire (CPAQ)-further validation including a confirmatory factor analysis and a comparison with the tampa scale of kinesiophobia. Eur J Pain. 2009;13(7):760-8.

50. Reneman MF, Dijkstra A, Geertzen JH, Dijkstra PU. Psychometric properties of chronic pain acceptance questionnaires: a systematic review. Eur J Pain. 2010;14(5):457-65.

51. Goubert L, Craig KD, Vervoort T, Morley S, Sullivan MJ, de C Williams AC, et al. Facing others in pain: the effects of empathy. Pain. 2005;118(3):285-8.

52. Goubert L, Crombez G, Van Damme S, Vlaeyen JW, Bijttebier P, Roelofs J. Confirmatory factor analysis of the tampa scale for kinesiophobia: invariant two-factor model across low back pain patients and fibromyalgia patients. Clin J Pain. 2004;20(2): $103-10$.

53. Vlaeyen JW, Kole-Snijders AM, Boeren RG, van Eek H. Fear of movement/(re)injury in chronic low back pain and its relation to behavioral performance. Pain. 1995;62(3):363-72.

54. Nicholas MK. In: Self-efficacy and chronic pain. Paper presented at the annual conference of the British psychological society. St Andrews; 1989.

55. Sullivan M, Bishop S, Pivik J. The pain catastrophizing scale: development and validation. Psychol Assess. 1995;7(4):524-32.

56. Van Damme S, Crombez G, Bijttebier P, Goubert L, Van Houdenhove B. A confirmatory factor analysis of the pain catastrophizing scale: invariant factor structure across clinical and nonclinical populations. Pain. 2002;96(3):319-24.

57. Crombez G, Vlaeyen JW, Heuts PH, Lysens R. Pain-related fear is more disabling than pain itself: evidence on the role of painrelated fear in chronic back pain disability. Pain. 1999;80(1-2): 329-39.

58. Crombez G, Eccleston C, Baeyens F, Eelen P. When somatic information threatens, catastrophic thinking enhances attentional interference. Pain. 1998;75(2-3):187-98.

59. Severeijns R, van den Hout MA, Vlaeyen JW, Picavet HS. Pain catastrophizing and general health status in a large Dutch community sample. Pain. 2002;99(1-2):367-76.

60. Venselaar K, Post M. Normering van de UCL voor mannen en vrouwen met chronische lage rugpijn [Norms of the UCL for men and women with chronic low back pain]. Nederlands Tijdschrift voor de Psychologie. 2004;59:132-4.

61. Schreurs PJG, Willige van de G, Brosschot JF, Tellegen B, Graus GMH. De Utrechtse coping lijst: UCL. Omgaan met problemen en gebeurtenissen, herziene handleiding. [the Utrecht's coping list: UCL. Managing problems and events, revised manual]. Lisse: Swets Test Publishers; 1993.

62. Kerns RD, Turk DC, Rudy TE. The West Haven Yale multidimensional pain inventory (WHYMPI). Pain. 1985;23(4):345-56.

63. Lousberg R, Van Breukelen GJ, Groenman NH, Schmidt AJ, Arntz A, Winter FA. Psychometric properties of the multidimensional pain inventory, Dutch language version (MPI-DLV). Behav Res Ther. 1999;37(2):167-82.

64. Tuomi K, Ilmarinen J, Jahkola A, Katajarinne L, Tulkki A. Work ability index. Helsinki: Finnish Institute of Occupational Health; 1998.

65. de Zwart BC, Frings-Dresen MH, van Duivenbooden JC. Testretest reliability of the work ability index questionnaire. Occup Med (Lond). 2002;52(4):177-81.

66. Kessler RC, Barber C, Beck A, Berglund P, Cleary PD, McKenas $D$, et al. The World Health Organization health and work performance questionnaire (HPQ). J Occup Environ Med. 2003; 45(2):156-74.

67. Kessler RC, Ames M, Hymel PA, Loeppke R, McKenas DK, Richling DE, et al. Using the World Health Organization health and work performance questionnaire (HPQ) to evaluate the indirect workplace costs of illness. J Occup Environ Med. 2004;46(6 Suppl):S23-37.

68. Veldhoven vM. Psychosociale arbeidsbelasting en werkstress [Psychosocial job demand and work stress]. Dissertation. University of Groningen, The Netherlands; 1996.

69. U.S. Department of Labor. The revised handbook for analyzing jobs. 4th edn. Indianapolis: JIST Works Inc; 1991.

70. Hildebrandt VH, Bongers PM, van Dijk FJ, Kemper HC, Dul J. Dutch musculoskeletal questionnaire: description and basic qualities. Ergonomics. 2001;44(12):1038-55.

71. Cohen J. Statistical power analysis for the behavioral sciences. 2nd ed. Hillsdale, New York: Lawrence Erlbaum; 1988.

72. Norman GR, Sloan JA, Wyrwich KW. Interpretation of changes in health-related quality of life - the remarkable universality of half a standard deviation. Med Care. 2003;41(5):582-92.

73. Nygard CH, Luopajarvi T, Ilmarinen J. Musculoskeletal capacity and its changes among aging municipal employees in different work categories. Scand J Work Environ Health. 1991;17(Suppl 1):110-7.

74. Kaila-Kangas L, Keskimaki I, Notkola V, Mutanen P, Riihimaki $\mathrm{H}$, Leino-Arjas P. How consistently distributed are the socioeconomic differences in severe back morbidity by age and gender? A population based study of hospitalisation among Finnish employees. Occup Environ Med. 2006;63(4):278-82.

75. Hagen KB, Holte HH, Tambs K, Bjerkedal T. Socioeconomic factors and disability retirement from back pain: a 1983-1993 population-based prospective study in Norway. Spine (Phila Pa 1976). 2000;25(19):2480-2487.

76. Hagen KB, Tambs K, Bjerkedal T. What mediates the inverse association between education and occupational disability from back pain? A prospective cohort study from the Nord-Trondelag health study in Norway. Soc Sci Med. 2006;63(5):1267-75.

77. Saastamoinen P, Laaksonen M, Lahelma E, Leino-Arjas P. The effect of pain on sickness absence among middle-aged municipal employees. Occup Environ Med. 2009;66(2):131-6.

78. Schmidt CO, Raspe H, Kohlmann T. Graded back pain revisited-do latent variable models change our understanding of severe back pain in the general population? Pain. 2010;149(1): $50-6$.

79. Hosmer DW, Lemeshow S. Applied logistic regression. 2nd ed. New York: Wiley; 2000.

80. Reitsma B, Meijler WJ. Pain and patienthood. Clin J Pain. 1997;13(1):9-21.

81. de Vries HJ, Brouwer S, Groothoff JW, Geertzen JH, Reneman MF. Staying at work with chronic nonspecific musculoskeletal 
pain: a qualitative study of workers' experiences. BMC Musculoskelet Disord. 2011;12:126.

82. Staal JB, Hlobil H, Twisk JW, Smid T, Koke AJ, van Mechelen W. Graded activity for low back pain in occupational health care: a randomized, controlled trial. Ann Intern Med. 2004;140(2): 77-84.

83. Smeets RJ, Vlaeyen JW, Hidding A, Kester AD, van der Heijden GJ, Knottnerus JA. Chronic low back pain: physical training, graded activity with problem solving training, or both? The oneyear post-treatment results of a randomized controlled trial. Pain. 2008;134(3):263-76.

84. Schaafsma F, Schonstein E, Ojajarvi A, Verbeek J. Physical conditioning programs for improving work outcomes among workers with back pain. Scand J Work Environ Health. 2011; 37(1):1-5.

85. Feuerstein M, Thebarge R. Perceptions of disability and occupational stress as discriminators of work disability in patients with chronic pain. J Occup Rehabil. 1991;1(3):185-95.

86. Grotle M, Vollestad NK, Veierod MB, Brox JI. Fear-avoidance beliefs and distress in relation to disability in acute and chronic low back pain. Pain. 2004;112(3):343-52.

87. Kuijer W, Groothoff JW, Brouwer S, Geertzen JH, Dijkstra PU. Prediction of sickness absence in patients with chronic low back pain: a systematic review. J Occup Rehabil. 2006;16(3):439-67.

88. Loisel P, Buchbinder R, Hazard R, Keller R, Scheel I, van Tulder $\mathrm{M}$, et al. Prevention of work disability due to musculoskeletal disorders: the challenge of implementing evidence. J Occup Rehabil. 2005;15(4):507-24.

89. Waddell G, Burton AK, Kendall NAS. Vocational rehabilitation. What works, for whom, and when? London: TSO; 2008.

90. Howard KJ, Mayer TG, Gatchel RJ. Effects of presenteeism in chronic occupational musculoskeletal disorders: stay at work is validated. J Occup Environ Med. 2009;51(6):724-31.

91. van der Roer N, Ostelo RW, Bekkering GE, van Tulder MW, de Vet HC. Minimal clinically important change for pain intensity, functional status, and general health status in patients with nonspecific low back pain. Spine (Phila Pa 1976). 2006;31(5): 578-582.

92. Ostelo RW, Deyo RA, Stratford P, Waddell G, Croft P, Von Korff M, et al. Interpreting change scores for pain and functional status in low back pain: towards international consensus regarding minimal important change. Spine (Phila Pa 1976). 2008; 33(1):90-94.

93. Gheldof EL, Vinck J, Vlaeyen JW, Hidding A, Crombez G. The differential role of pain, work characteristics and pain-related fear in explaining back pain and sick leave in occupational settings. Pain. 2005;113(1-2):71-81.

94. Langley P, Muller-Schwefe G, Nicolaou A, Liedgens H, Pergolizzi J, Varrassi G. The impact of pain on labor force participation, absenteeism and presenteeism in the European union. J Med Econ. 2010;13(4):662-72.

95. Andersen LL, Mortensen OS, Hansen JV, Burr H. A prospective cohort study on severe pain as a risk factor for long-term sickness absence in blue- and white-collar workers. Occup Environ Med. 2011;68(8):590-2.

96. Saastamoinen P, Leino-Arjas P, Laaksonen M, Martikainen P, Lahelma E. Pain and health related functioning among employees. J Epidemiol Community Health. 2006;60(9):793-8.

97. Elfving B, Asell M, Ropponen A, Alexanderson K. What factors predict full or partial return to work among sickness absentees with spinal pain participating in rehabilitation? Disabil Rehabil. 2009;31(16):1318-27.

98. Anema JR, Schellart AJ, Cassidy JD, Loisel P, Veerman TJ, van der Beek AJ. Can cross country differences in return-to-work after chronic occupational back pain be explained? An exploratory analysis on disability policies in a six country cohort study. J Occup Rehabil. 2009;19(4):419-26. 